\title{
Determination the Effect of Gamma Radiation and Thermal Neutron on PM-355 Detector by Using FTIR Spectroscopy
}

\author{
Hussain Ali Al-Jobouri \\ Department of Physics, College of Science, AL-Nahrain University, Baghdad, Iraq \\ Email: hahmed54@gmail.com
}

Received 27 May 2015; accepted 20 July 2015; published 23 July 2015

Copyright (C) 2015 by author and Scientific Research Publishing Inc.

This work is licensed under the Creative Commons Attribution International License (CC BY). http://creativecommons.org/licenses/by/4.0/

\section{(c) (7) Open Access}

\begin{abstract}
The effect of gamma on nuclear track detector type PM-355 (at the dose range 200 to $1600 \mathrm{kGy}$ ) and thermal neutron (flux $10^{5} \mathrm{n} \cdot \mathrm{cm}^{-2} \cdot \mathrm{s}^{-1}$ ) was calculated by using of two irradiation methods. First method $(G+N)$ was an irradiation PM-355 detector by gamma radiation and then irradiation by thermal neutrons, and another method $(\mathrm{N}+\mathrm{G})$ was irradiated by thermal neutrons and then gamma radiation. FTIR-spectroscopy was used to measure the change in deferent of transmission percent $\Delta \mathrm{T} \%$ at the wavenumber $1260 \mathrm{~cm}^{-1}$ with wavenumber $2962 \mathrm{~cm}^{-1}[\Delta \mathrm{T} \%]_{1260-2962}$ and wavenumber $1138 \mathrm{~cm}^{-1}[\Delta \mathrm{T} \%]_{1260-1138}$. The values of $[\Delta \mathrm{T} \%]_{1260-2962}$ and $[\Delta \mathrm{T} \%]_{1260-1138}$ were increasing with the increase of gamma irradiation with maximum response at $820 \mathrm{kGy}$ and then drop after this dose until to $1600 \mathrm{kGy}$. This study determined the linear equations relation between the effect of gamma radiation on PM-355 detector and the change of $[\Delta \mathrm{T} \%]_{1260-2962}$ and $[\Delta \mathrm{T} \%]_{1260-1138}$, and this change appeared in $(N+G)$ irradiation method better than in $(G+N)$ irradiation method. The appearance of wavenumber $2964 \mathrm{~cm}^{-1}$ in $(G+N)$ irradiation method referred to alkyl asymmetry $\mathrm{C}-\mathrm{H}$ bond stretched out of skelated plane after changes in chemical structure of PM-355 detector by gamma or neutrons radiation.
\end{abstract}

\section{Keywords}

PM-355, Nuclear track Detectors, Gamma Radiation, Thermal Neutron, FTIR-Spectroscopy

\section{Introduction}

The effect of gamma and neutron radiation on non conducting polymers as polyallyl diglycol carbonate-PADC [1], polyethylene terephthalate-PET [2], Makrofol-KGand PM-355 have been demonstrated in many studies [3]. PM-355 represents one of the types of nuclear track detectors-NTDs and the changes of PM-355 including 
of optical, chemical and structural properties. These properties are measured by using different techniques. The techniques which are used to study the changes in the PM-355 are X-ray diffracted—XRD [1] [4], micro-raman spectroscopy [1], UV-visible spectroscopy [5] and Fourier transformer infrared-FTIR [6]. The numbers of tracks per incident neutron of the CR-39, PM-355 and PM-500 track detectors have been investigated for each detector [7]. Also, it is obtained that the thermal properties and the absorbance of the PM-355 are dependent on the neutron energy [8]. While some studies [9] indicate that each of the bulk etch rate- $-V_{b}$, the track etch rate$\mathrm{V}_{\mathrm{t}}$ and the sensitivity $-\mathrm{V}$ of the PM-355 detectors increase with the high gamma absorbed dose up to $500 \mathrm{kGy}$. The absorption spectra which are measured by UV-visible spectroscopy of PM-355 with gamma irradiation dose within 300 - $1600 \mathrm{kGy}$ change with the increase of radiation dose [5]. The energy gap of PM-355 is decreasing with absorbed dose systematically and it can be used as a second tool to determine the dosimeter range [5]. The effects of gamma at the range 10 - $250 \mathrm{kGy}$ and electron beam irradiation on the color changes of PM-355 nuclear track detector are investigated [10].

The modification of chemical and structural properties of PM-355 films is investigated after the irradiation of $1.25 \mathrm{MeV}{ }^{60} \mathrm{Co}$ gamma-radiations at doses ranging from 0 - $675 \mathrm{kGy}$ [1], and shows that the Raman spectra of the films are highly disordered at the highest gamma dose. Although it shows that the analysis reveals a significant increase in micro strain, dislocation density and distortion parameter with an increase of gamma dose after the study of the XRD pattern of PM-355. As well as, many physical properties of NTDs change with the effects of gamma radiation and one of these properties is DC-conductivity. These DC-conductivity measurements of PM-555 indicate that both the degree of ordering or disordering and the anisotropic character of the PM-555 are dependent on the gamma dose at the range 5 - $63 \mathrm{kGy}$ by using of X-ray diffraction-XRD and refractive index [4]. While the dielectric constant of PM-355 is absorbed, the gamma irradiation dose will increase [11]. In 2013 Emad Hassan Aly [12] obtained the microstructural investigation of PM-355 from the response of low dose gamma irradiationby by using a positron annihilation lifetime study. On other side, the studies which include both the effects of gamma and neutron radiation are taken into account [13] [14].

The estimation of gamma and neutron dose based on the use of changes in activation energy of degradation of the Lexan and CR-39 track detectors is due to gamma-neutron irradiation as a means of dosimetry [15]. And calculating the linear relationship observed between the decrease in activation energy and the gamma-neutron dose being received by the detectors suggests the possibility of the use of these detectors as gamma and neutron dosimeters [15]. Abdel Raouf et al. 2013 [14] studied the effects of irradiated gamma rays, X-rays and alpha particles on CR-39 by FTIR-spectroscopy, which show the optical density of the detector was calculated and then it was used to determine alpha range [14]. In this study, the relation between the radiation dose of gamma radiation and thermal neutron on PM-355 detector and some values of transmission percent which measured by FTIR-spectroscopy will be determined.

\section{Experimental}

Polymetylen type PM-355 sheets was perpetrated with size $2 \times 3 \mathrm{~cm}$ dimensions and $500 \mu \mathrm{m}$ thickness. The source of gamma radiation was Co-60 with dose rate $4.23 \mathrm{~Gy} / \mathrm{min}$ (423 $\mathrm{Rad} / \mathrm{min}$ ) at the dose range 300 - 1600 $\mathrm{kGy}$. Thermal neutron radiation from ${ }^{241} \mathrm{Am}-{ }^{9}$ Be with neutron flux $10^{5} \mathrm{n} \cdot \mathrm{cm}^{-2} \cdot \mathrm{s}^{-1}$. The PM-355 sheets were irradiated by two irradiation methods, first method was irradiated PM-355 sheets by thermal neutron radiation for $24 \mathrm{~h}$ and then irradiation with gamma radiation at the range 300 - $1600 \mathrm{kGy}$ which labeled (N + G) irradiation method. The second method was irradiation with gamma radiation at the range 300 - $1600 \mathrm{kGy}$ and then irradiation by thermal neutron radiation also, for $24 \mathrm{~h}$ which labeled $(\mathrm{G}+\mathrm{N})$ irradiation method. The wave numbers was measured and analyzed by FTIR-spectrometer model FTIR-8300 from Shimadzu Company. This technique was operated to measuring of transmission percent-T\% for irradiated PM-355 sheets at the wavenumber range $400-4000 \mathrm{~cm}^{-1}$.

\section{Results and Discussion}

Figure 1 shows FTIR-spectrum or un-irradiated PM-355 detector at the wavenumber range from $400 \mathrm{~cm}^{-1}$ to $4000 \mathrm{~cm}^{-1}$. The mean peaksof wavenumbers were $2962 \mathrm{~cm}^{-1}, 1743 \mathrm{~cm}^{-1}, 1260 \mathrm{~cm}^{-1}, 1134 \mathrm{~cm}^{-1}$, and 474.49 $\mathrm{cm}^{-1}$. Figure 1 takes as un-irradiated PM-355 sample detector which compare with other irradiated samples. The calculation of FTIR-spectrum measurement for $(N+G)$ and $(G+N)$ irradiation methods depend on the change different in transmission percent-T\%. 


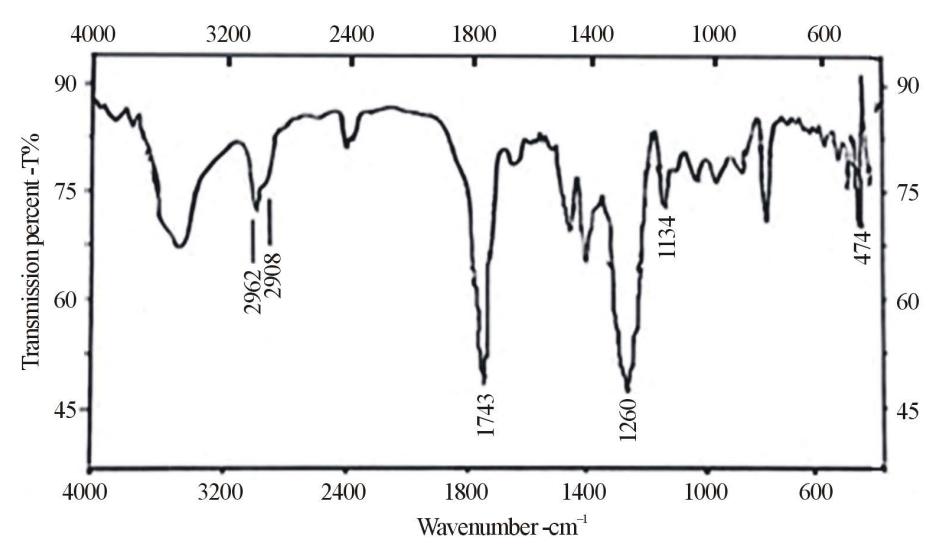

Figure 1. FTIR-spectrum at the range $400-4000 \mathrm{~cm}^{-1}$ for unirradiated PM-355 detector with wavenumbers 2962, 2908, 1260, $1134 \mathrm{~cm}^{-1}$.

The change different determined by measurement the transmission percent-T\% of the wavenumber $1260 \mathrm{~cm}^{-1}$ with wavenumber $2963 \mathrm{~cm}^{-1}[\Delta \mathrm{T} \%]_{1260-2962}$ and the change of wavenumber $1260 \mathrm{~cm}^{-1}$ with wavenumber 1138 $\mathrm{cm}^{-1}[\Delta \mathrm{T} \%]_{1260-1138}$ which calculated by following equations.

$$
\begin{aligned}
{[\Delta \mathrm{T} \%]_{1260-2962} } & =[\mathrm{T} \%]_{1260}-[\mathrm{T} \%]_{2962} \\
{[\Delta \mathrm{T} \%]_{1260-1138} } & =[\mathrm{T} \%]_{1260}-[\mathrm{T} \%]_{1138}
\end{aligned}
$$

where $[\Delta \mathrm{T} \%]_{1260-2962}$ and $[\Delta \mathrm{T} \%]_{1260-1138}$ are the change different in transmission percent-T\% of the wavenumber $1260 \mathrm{~cm}^{-1}$ with wavenumber $2963 \mathrm{~cm}^{-1}$ and with wavenumber $1138 \mathrm{~cm}^{-1}$ respectively. The uses of the wavenumber $1260 \mathrm{~cm}^{-1}$ in above equations since this wavenumber was continue appear for all PM-355 FTIR spectrum with gamma irradiation dose. From Figure 2(a) show the change in the value of $[\Delta T \%]_{1260-2962}$ for $(N+G)$ irradiation method was increase with increase of gamma radiation and high linearity sloop with maximum response at $820 \mathrm{kGy}$ and then drop after this dose until to $1600 \mathrm{kGy}$. The maximum gamma response was show the high sensitivity of the PM-355 detector increase with high gamma absorbed dose up to $500 \mathrm{kGy}$ [9]. Where in this study obtained the maximum response appear at $820 \mathrm{kGy}$. As shown the relation in Figure 2(b) between the value of $[\Delta \mathrm{T} \%]_{1260-1138}$ for $(\mathrm{N}+\mathrm{G})$ irradiation which increase with gamma irradiation dose. The behavior of this relation was low linearity slop with maximum response until to $820 \mathrm{kGy}$ and then drop after this dose until to 1600 kGy. Figure 3(a) and Figure 3(b) determine from Figure 2(a) and Figure 2(b) respectively at the range of irradiation dose 0 - $800 \mathrm{kGy}$. Equations (3) and (4) were calculated by straight line between $[\Delta \mathrm{T} \%]_{1260-2962}$ and $[\Delta \mathrm{T} \%]_{1260-1138}$ with gamma radiation dose-D as shown in Figure 3(a) and Figure 3(b) respectively.

$$
\begin{aligned}
& {[\Delta \mathrm{T} \%]_{1260-2962}=0.047 \mathrm{D}+23.88} \\
& {[\Delta \mathrm{T} \%]_{1260-1138}=0.039 \mathrm{D}+22.26}
\end{aligned}
$$

where D: gamma irradiation dose (kGy).

Figure 3(a) and Figure 3(b) show the relation between $[\Delta \mathrm{T} \%]_{1260-1138}$ and $[\Delta \mathrm{T} \%]_{1260-2962}$ with PM-355 detector irradiation dose by gamma radiation respectively. The Equations (3) and (4) may be use to assessment of gamma radiation after exposure to neutron source as $(\mathrm{N}+\mathrm{G})$ irradiation method until to $820 \mathrm{kGy}$. The linearity of straight line which appears in Figure 3(a) by Equation (3) for change different at wavenumber $2962 \mathrm{~cm}^{-1}$ was better than the linearity of straight line which appear in Figure 3(b) by Equation (4). The slope of straight line was equal to 0.047 which determine by Equation (3) and this value of slope is nearly to slope value of 0.030 which calculate also for PM-355 detector between absorption coefficient in unit $\left(\mathrm{mm}^{-1}\right)$ as a gamma radiation with gamma irradiation response [5].

The change in wavenumber $2962 \mathrm{~cm}^{-1}$ with gamma irradiation dose was also appear in Raman spectroscopy technique [15] when measurement the Raman intensity with Raman shift in unit $\mathrm{cm}^{-1}$ from gamma irradiation dose $150 \mathrm{kGy}$ to $670 \mathrm{kGy}$ for PM-355 detector. Where for $(\mathrm{G}+\mathrm{N})$ irradiation method the change different in the 


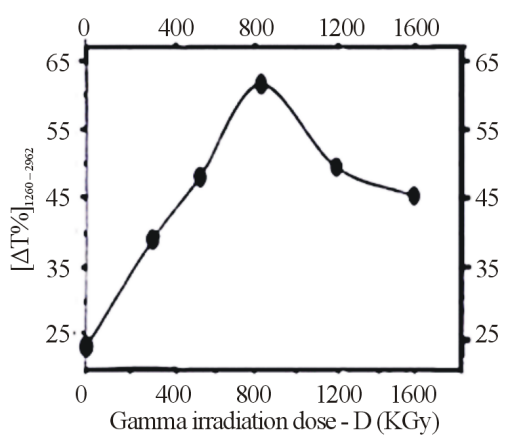

(a)

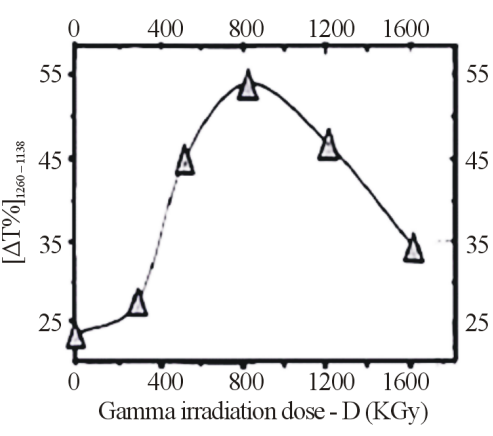

(b)

Figure 2. Change different in transmission percent- $\Delta \mathrm{T} \%$ for $(\mathrm{N}+\mathrm{G})$ irradiation method with gamma radiation to PM-355 detector at: (a): $[\Delta \mathrm{T} \%]_{1260-2962}$, (b): $[\Delta \mathrm{T} \%]_{1260-1138}$.

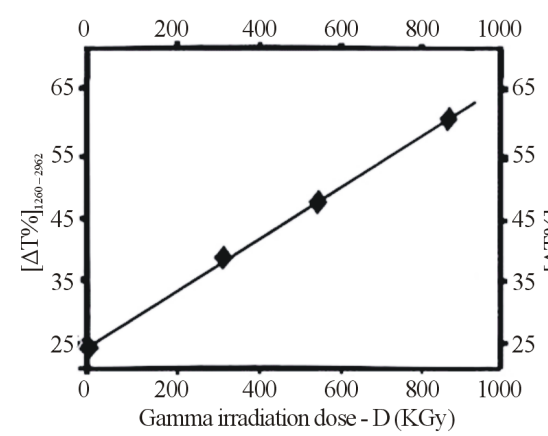

(a)

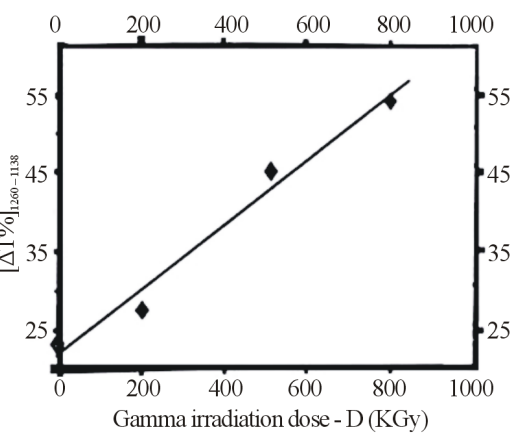

(b)

Figure 3. The relationship between the change different transmission percent with gamma irradiation dose for $(\mathrm{N}+\mathrm{G})$ irradiation method to PM-355 detector at (a): $[\Delta \mathrm{T} \%]_{1260-2962},(\mathrm{~b}):[\Delta \mathrm{T} \%]_{1260-1138}$.

logarithmic values of transmission percent- $\mathrm{T} \%[\Delta \mathrm{T} \%]_{1260-2962}$ and $[\Delta \mathrm{T} \%]_{1260-1138}$ for PM-355 detector which irradiation with gamma irradiation dose from $300 \mathrm{kGy}$ to $1600 \mathrm{kGy}$ were calculated as shown in Figure 4(a) and Figure 4(b) respectively. Equation (5) and Equation (6) reflected the gamma irradiation dose-Dat (G + N) irradiation method after determine the values of $[\Delta \mathrm{T} \%]_{1260-2962}$ and $[\Delta \mathrm{T} \%]_{1260-1138}$ which calculation from Figure 4(a) and Figure 4(b) respectively.

$$
\begin{aligned}
& {[\Delta \mathrm{T} \%]_{1260-2962}=0.098 \mathrm{D}+20.92} \\
& {[\Delta \mathrm{T} \%]_{1260-1138}=0.060 \mathrm{D}+22.42}
\end{aligned}
$$

where D: gamma irradiation dose (kGy).

The straight line obtained in Figure 4(a) and Figure 4(b) may be use to assessment of gamma radiation dose in PM-355 detector after known the value of $[\Delta \mathrm{T} \%]_{1260-2962}$ and $[\Delta \mathrm{T} \%]_{1260-1138}$.

Figure 5 shows the change of wavenumber $2962 \mathrm{~cm}^{-1}$ in $(G+N)$ irradiation method with gamma irradiation dose from $300 \mathrm{kGy}$ to $1600 \mathrm{kGy}$. The change in shape of spectrum at wavenumber $2962 \mathrm{~cm}^{-1}$ may be also use to reflect the effect of neutron source after irradiation with gamma radiation dose. Irradiation method $(G+N)$ also, shown the wavenumber $2908 \mathrm{~cm}^{-1}$ which obtained in un-irradiation sample was disappear with increase of gamma radiation dose until to $1600 \mathrm{kGy}$, Figure 6. Where there was appearance of wavenumber $2920 \mathrm{~cm}^{-1}$ at the radiation dose1600 kGy which lead to C-H stretch anti symmetry [15]. And this anti symmetry related with ordinary or disordinary and the anisotropic charter the detector are dependent on the gammadose [4].

The gamma radiation dose response at wavenumber $2962 \mathrm{~cm}^{-1}$ was appear as a result of alkyl asymmetry C-H bond stretch out of skelated plane [14] after change in chemical structure of PM-355 by gamma or neutron radiation. But the gamma radiation response of wavenumber $1265 \mathrm{~cm}^{-1}$ was appear as a result to deformation of a 


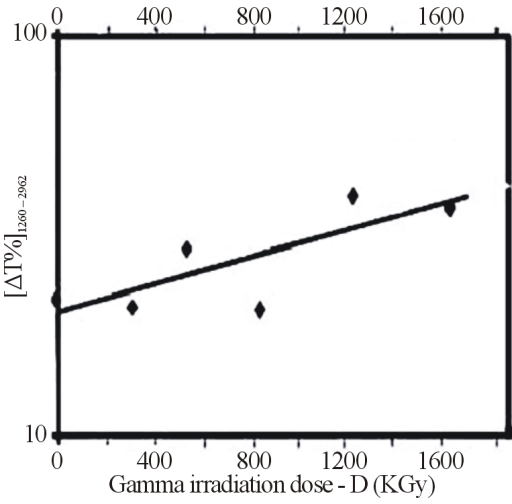

(a)

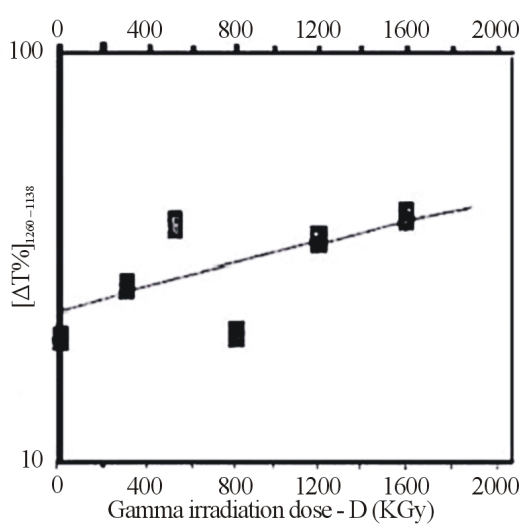

(b)

Figure 4. The relationship between the change different transmission percent with gamma irradiation dose for $(\mathrm{G}+\mathrm{N})$ irradiation method to PM-355 detector at (a): $[\Delta \mathrm{T} \%]_{1260-2962},(\mathrm{~b}):[\Delta \mathrm{T} \%]_{1260-1138}$.

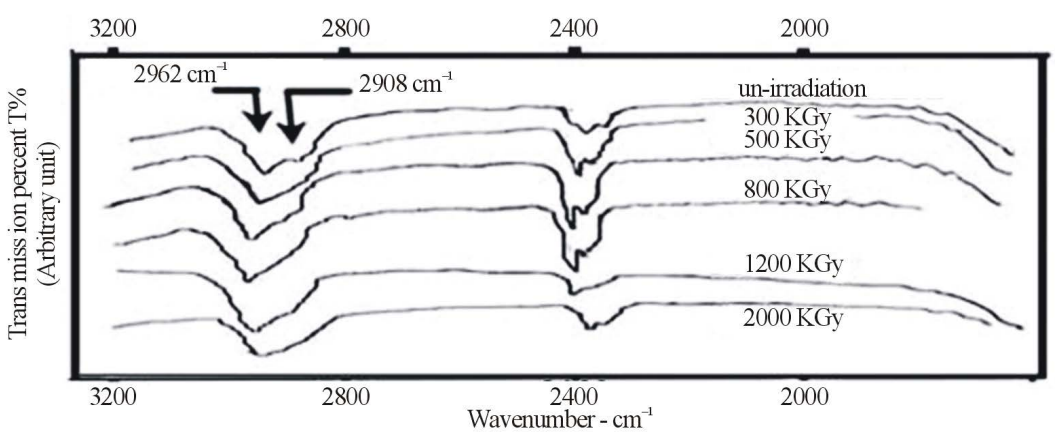

Figure 5. The change in wavenumber $2908 \mathrm{~cm}^{-1}$ in FTIR-spectrum of PM-355 detector for $(\mathrm{G}+\mathrm{N})$ radiation method with gamma irradiation dose from $300 \mathrm{KGy}$ to $1600 \mathrm{KGy}$.

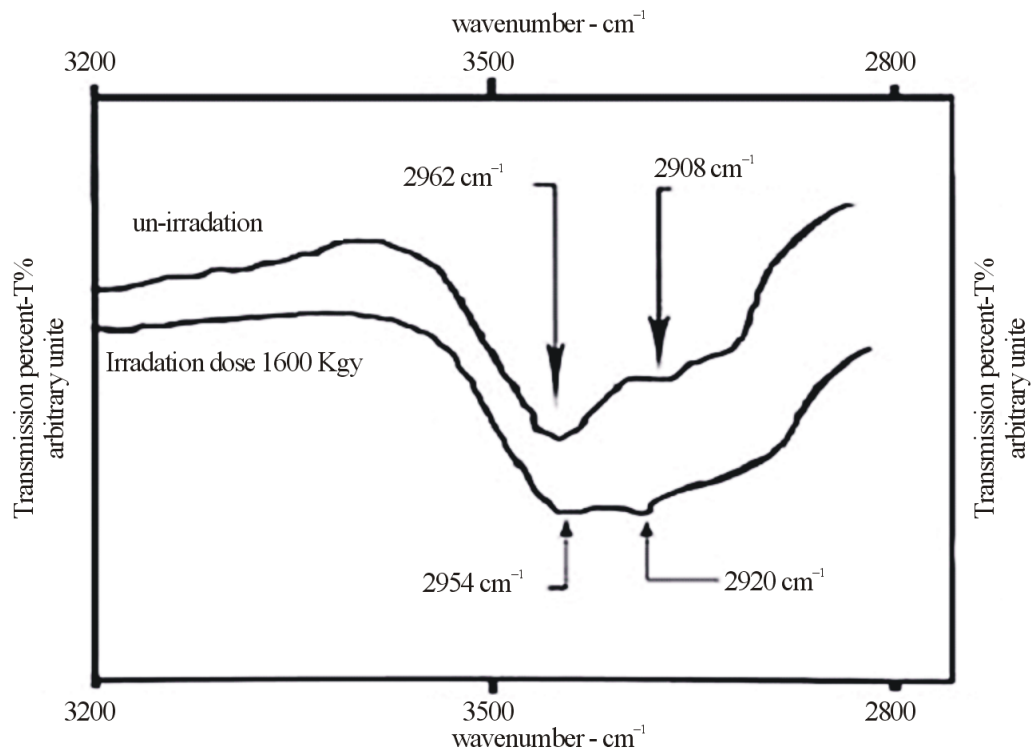

Figure 6. The appearance of the new wavenumber $2920 \mathrm{~cm}^{-1}$ for irradiated PM-355 detector to $1600 \mathrm{kGy}$ by $(\mathrm{G}+\mathrm{N})$ irradiation method comparing with unirradiated detector. 
weak absorption for C-Cbond for structure of PM-355. The behavior of relation between $[\Delta \mathrm{T} \%]_{1260-2962}$ and gamma irradiation dose in $(\mathrm{N}+\mathrm{G})$ irradiation method for PM-355 was nearly the same behavior of absorption coefficient gamma radiation dose [5]. That means the effect of thermal neutron radiation before gamma radiation no adding any change in chemical structure of PM-355 detector. While at $(G+N)$ irradiation method the effect of neutron radiation was high appear for PM-355 detector which irradiation with gamma radiation before neutron exposure. This reflects the effect of gamma on PM-355 was increase in photo degradation [11] which lead to formed electron and hole take place causing changing in wave number in FTIR spectrum.

\section{Conclusion}

The study indicates the possibility of the using of nuclear track detector type PM-355 for the estimation of gamma radiation dose during thermal neutron effects based on the use of changes in the transmission percent-T\% from FTIR-spectroscopy. And it indicates that each of the bulk etch rate- $V_{b}$, the track etch rate $-V_{t}$ and the sensitivity-V of the PM-355 detectors increase with the high gamma absorbed dose up to $500 \mathrm{kGy}$. And it can use PM-355 detector as the gamma radiation dosimeter at this exposure range by using of the change measurements of the difference in transmission percent-T\% $[\Delta \mathrm{T} \%]_{1260-2962}$ and $[\Delta \mathrm{T} \%]_{1260-1138}$ from FTIR-spectroscopy.

\section{References}

[1] Vijay Kumar, R., Sonkawade, G. and Dhaliwal, A.S. (2012) Gamma Irradiation Induced Chemical and Structural Modifications in PM-355 Polymeric Nuclear Track Detector Film. Nuclear Instruments and Methods in Physics Research, 290, 59-63. http://dx.doi.org/10.1016/j.nimb.2012.08.029

[2] Mallick, B., Behera, R.C. and Patel, T. (2005) Analysis of Microstrain in Neutron Irradiated Polyester Fibre by X-Ray Diffraction Technique. Bulletin of Materials Science, 28, 593-598. http://dx.doi.org/10.1007/BF02706348

[3] Tayel, A., Zaki, M.F., El Basaty, A.B. and Hegazy, T.M. (2015) Modifications Induced by Gamma Irradiation to Makrofol Polymer Nuclear Track Detector. Journal of Advanced Research, 6, 219-224. http://dx.doi.org/10.1016/j.jare.2014.01.005

[4] Nouh, S.A. (2004) Physical Changes Associated with Gamma Doses of PM-555 Solid-State Nuclear Track Detector. Radiation Measurements, 38, 167-172. http://dx.doi.org/10.1016/j.radmeas.2003.11.004

[5] Al-Mashhadani, N.J.H. (2009) $\gamma$-Irradiation Effect on the Optical Constants, and the Electric Loss of PM-355. Enginering and Technical Journal, 32, 1158-1168.

[6] Saad, A.F., Atwa, S.T., Yokota, R. and Fujii, M. (2005) Radiation-Induced Modifications on Spectroscopic and Thermal Properties of CR-39 and SR-90 Nuclear Track Detectors. Radiation Measurements, 40, 780-784. http://dx.doi.org/10.1016/j.radmeas.2005.03.018

[7] Czyżewski, T., Jaskóła, M., Korman, A., Pszona, S., Sadowski, M. and Szydłowski, A. (1997) On the Interpretation of CR-39, PM-355 and PM-500 Track Detector Response to $14.9 \mathrm{MeV}$ Neutrons. Nuclear Instruments and Methods in Physics Research, 132, 724-727. http://dx.doi.org/10.1016/S0168-583X(97)00502-8

[8] Nouh, S.A., Abdel Naby, A. and El Hussieny, H.M. (2007) Fast Neutron Irradiation Effects in PM-355. Applied Radiation and Isotopes, 65, 1173-1178.

[9] Abu-Jarad, F., Hala, A.M. and Farhat, M. (1997) Variation of PM-355 Properties by High Gamma Absorbed Doses. Radiation Measurements, 27, 13-17. http://dx.doi.org/10.1016/S1350-4487(96)00135-7

[10] Nouh, S.A. and Bahareth, R.A. (2012) Color Changes in Gamma- and Electron-Beam-Irradiated PM-355 Nuclear Track Detector. Radiation Effects and Defects in Solids, 167, 111-119. http://dx.doi.org/10.1080/10420150.2011.607455

[11] Al-Karmi, A.M. (2006) Impedance Spectroscopy of Gamma Irradiated PM-355. Radiation Measurements, 41, $209-212$. http://dx.doi.org/10.1016/j.radmeas.2005.07.023

[12] Aly, E.H. (2013) Microstructural Investigation of PM-355 Nuclear Track Detector Subjected to Low-Dose Gamma Irradiation: A Positron Annihilation Lifetime. Materials Sciences and Applications, 4, 622-629. http://dx.doi.org/10.4236/msa.2013.410076

[13] Kalsi, P.C. (2009) Gamma and Neutron Dose Measurements with Solid State Nuclear Track Detectors. Indian Journal of Physics, 83, 799-804. http://dx.doi.org/10.1007/s12648-009-0047-6

[14] Abdel Raouf, K.M. (2013) Study of CR-39 SSNDs Irradiated with Different Types of Radiation by FTIR Spectroscopy and $\alpha$-Range Determination. American Journal of Environmental Protection, 2, 53-57. http://dx.doi.org/10.11648/j.ajep.20130202.14

[15] Snyder, R.G., Hus, S.L. and Kriumm, S. (1978) Vibrational Spectra in the C-Hstretching Region and the Structure of the Polymethylene Chain. Specrtochimica Acta, 34A, 395-406. 